\title{
The Influence Of Sand Casting Mold Solidfication Pressure Variations To The Quality Of Al-Si Alloy Casting Product \\ Aprianur Fajri* and Basyirun
}

Department of Mechanical Engineering, Semarang State University

Received: 15 April 2018, Revised: 12 July 2018, Accepted: 20 July 2018

\begin{abstract}
The purpose of this study is to find The influence of the sand cast solidification pressure variations to the quality of an alloy Al-Si casting product. An experimental method was used in the study and the analysis of the data used descriptive analysis to explain the charts. The stages of researched process is preparation material and equipment; making the design and manufacture of a pattern; manufacture of the sand mold by $35,40,45,50$, and $55 \mathrm{~kg} / \mathrm{cm}^{2}$ pressure variation; casting process; observation of defect; measurement of the level roughness; microstructure examination; assay composition; and last test is hardness micro vickers test. The research results show that variations pressure $35 \mathrm{~kg} / \mathrm{cm}^{2}$ does not occur defect the needle at al. A defect of the needle that occur most frequently upon variations of the pressure of the $55 \mathrm{~kg} / \mathrm{cm}^{2}$ is as much as $0.62 \%$. Air cavities formed to variation pressure solidification $35 \mathrm{~kg} / \mathrm{cm}^{2}$ of $0.77 \%$ to the least, while in variation $55 \mathrm{~kg} / \mathrm{cm}^{2}$ happened the number of defect air cavities the most namely $3.96 \%$. The mold fall defect largest namely $1.95 \%$ happened to variation pressure $35 \mathrm{~kg} / \mathrm{cm}^{2}$. Defect of sand inclusion the least of $0.06 \%$ happened to variation pressure 55 $\mathrm{kg} / \mathrm{cm}^{2}$. Defect of fins formed due to variation pressure solidification sand mold experienced the number of been fluctuating, recorded high in early then decline and to high back in highest variation. The pressure variation $35 \mathrm{~kg} / \mathrm{cm}^{2}$ it has value roughness flattened 3.17 and products castings the most rough happened to sand mold solidification variation pressure $55 \mathrm{~kg} / \mathrm{cm}^{2}$, with on average of 5.44 . the degree of hardness highest of $141.8 \mathrm{VHN}$ happened to variation pressure $35 \mathrm{~kg} / \mathrm{cm}^{2}$ and lowest of 124.8 VHN happened to variation $55 \mathrm{~kg} / \mathrm{cm}^{2}$. Concluded that the solidification of pressure variations sand mold $45 \mathrm{~kg} / \mathrm{cm}^{2}$ produce castings products with the most optimal average in terms of the measurement of the defective; variation pressure solidification sand mold of sand casting $35 \mathrm{~kg} / \mathrm{cm}^{2}$ produce a smooth surface, and the higher pressure make surface castings becomes rougher; solidification of pressure variations and coarse sand mold $35 \mathrm{~kg} / \mathrm{cm}^{2}$ produce micro structure with smooth grains and becomes more violent along with increasing pressure; pressure variation $35 \mathrm{~kg} / \mathrm{cm}^{2}$ produce a hardest surface, the higher of the pressure variation it becoming violence number progressively lower.
\end{abstract}

Keywords : Pressure variations, sand casting, quality

\section{Introduction}

The metal casting is a process of making where metal products were disbursed in a smelting furnace then poured into the cavity mold like the original form of the cast to be made [1]. Metal processing to the like this has been found people since $4000 \mathrm{BC}$ [2]. Metals casting industry in indonesia are still relatively small and the quality of their products is still low. The impact is the local products was lost when compete with another products with better quality. The quality of a product is the parameter to measure good bad things based on criteria or specified standard [3]. One standard that can be used to measure the quality of a casting product is by using measurement of the physical and mechanical properties. Physical properties can be measured by using visually investigation, dimension inspecsion, metallography testing, and defects measurement. Mechanical properties is the ability of mate-

\footnotetext{
*Email: aprianurfajri96@gmail.com
}

rials for receives the force/ energy without inflict damage [4]. Mechanical properties of material include: violence, strenght, toughness, plasticity, stiffness, and plasticity. To measure mechanical properties of metal, we can use the some testing method, such as: hardness testing, bending test, impact test, etc.

A metal casting method the most used in indonesia is by using sand as a mold (sand casting) to cast aluminium - silicon ( Al - Si ). Aluminum-Silicon alloys are noted for their unique combination of desirable characteristics, including excellent castability and low density combined with good mechanical properties. Interestingly, there is no mention of wear resistance in the many published tabulations of the attributes of this class of alloys (see, for example, [5] [6]. In a comprehensive review of the wear characteristics of aluminum alloys, Eyre [7] remarks on the dearth of published information about the wear resistance of aluminum-silicon alloys, while acknowledging 
their increased application in environments demanding this physical characteristic. In the late 1950s, sand casting aluminum-silicon alloy cylinder blocks were manufactured for the automotive industry to take advantage of the light weight and good thermal conductivity offered by hypoeutectic alloys such as A356 and A380 [8]. Sand is the most prevalent molding medium, and various types of binders are used to bond the sand into useable molds [9]. One of the methods used to fabricate expendable molds is Molding of sand with a clay-water binder and mechanical compaction green-sand molding. Compared with a kind of other material, Al-Si are metal which is very tractable by the process, because has good castability. Castability includes factors such as fluidity, shrinkage, and resistance the ability of the alloy to withstand stresses developed by the contraction while cooling from the hot-short temperature range [9]. But when practice, still there are various the problem and it needs to further review.

While applications for aluminum-silicon alloys are currently centered in the automotive industry (which accounts for greater than $50 \%$ of the market), other applications in communications equipment, instrumentation, and small engines appear likely [10]. So, the casting product of Al-Si must have good in quality. The factor that can affect the quality of the casting product of Al-Si is the quality of the mold itself. If the mold has good quality, then product quality generated also be better. To the process of making molds, a lot of things to be noted that such as; kind of sand, a measure of grain sand, a kind of fastener, the moisture content of, and pressure compaction sand given.

Defective of rat tail, cracks, porosity, mold fall, air cavities, fins, sand inclusion, a rough surface, low violence and bad structure is one defect occurring most frequently in casting alloy Al-Si process. According to Vijay SJ [11], to meet its demands of aluminum pour market, we must focus on improving the quality of metal with development at the process of melting. The process of focused on elimination various cause, one of them is doing compaction sand mold with appropriate pressure.

\section{Material and Method}

The study is experimental research (DOE) with the design used one shot case study and a descriptive analysis have been incorporated in the study. The objective of the paper is to knows the effects of each parameter on the quality and presure variation wear. Some specimens will be made and would be used as a reference to determine the quality in terms of the physical and mechanical properties with different based on treatment given. Phases in this study consisting of :

\section{Preparation of tools and materials}

2. Make the frame of mold

3. Calibration of Measuring instrument
4. Making molds sand with variations compaction 35 , $40,45,50,55 \mathrm{~kg} / \mathrm{cm}^{2}$

5. The process of melting and pouring into the mold.

6. The process of testing.

\section{Result and discussion}

The tools and materials used during the study are: Hydraulic machine with pressure gauge, A smelting furnace and its elements, the camera, millimeters block paper, Microvickers hardness tester, spectrometer, roughness surface tester, and microscope metallurgy.

\section{Result and Discussion}

\subsection{Physical Properties}

The first test is visual inspection using milimeter block paper to measure the area of each defect. The specimen was photographed and printed on the milimeter block paper, then we calculate the defect area manually. We classifying the defect based on each characteristic. Then, the result of measurement compared with the total area of speciment. From this method, we have percentage data. So, the difference effect from each pressure variation will be known.

The result of measurement area of a needle defect displayed into the graphic formats as in a figure 1. Point on these graphs form polynomial line and can be analyzed with simple regression analysis.

Based on the data, sand casting mold compression pressure had an impact as much as $98.55 \%$ against the increase of the needle defect. While the rest would belong ( $100 \%-98.55 \%=1.45 \%$ ) influenced by the other variabel , such as: raw materials, a kind of an alloy, and a system of channels. The cause of the needle defect is about gases and water vapor in reaction are stuck and could not get out from the mold. Finally gas were forced to break into a liquid metal castings. The incident like this is happen very

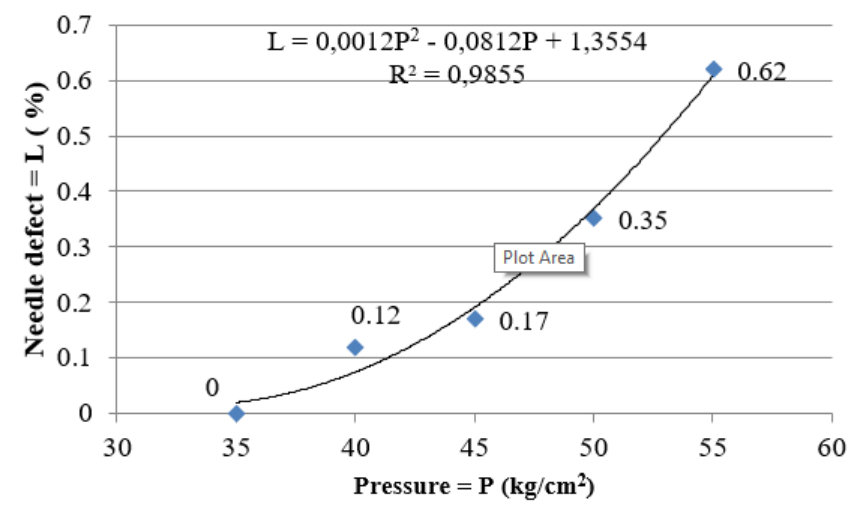

Figure 1. Variation pressure solidification of sand casting to the needle defect 


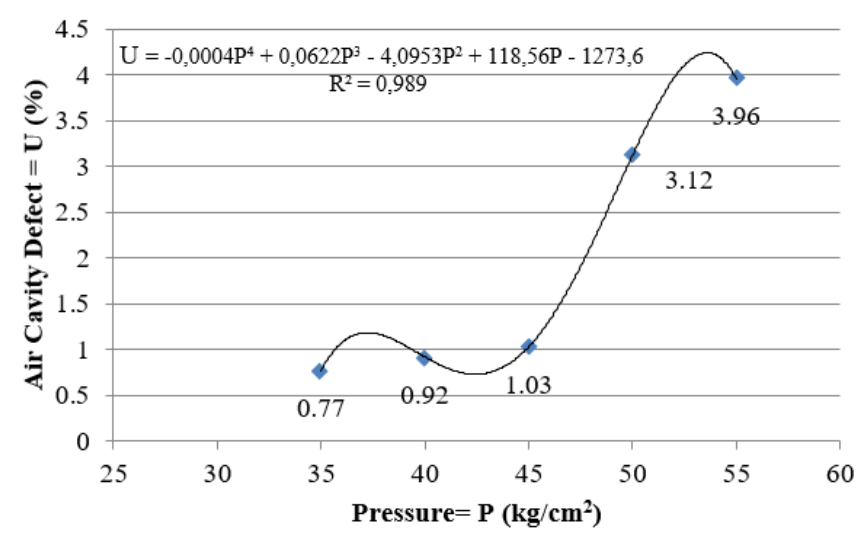

Figure 2. Relations variation pressure solidification of sand casting to the defect of air cavities

fast, when the process of freezing, formed a small cavity with a diameter of 1-2 mm like a needle prick. The biggest factors that affect this deffect is the permeability of sand mold. The bigger permeability of sand mold, so gas / water vapor would be easy out, otherwise, while the permeability is small, the gasses / water vapor would have been difficult to out.

The defect of air cavities shown in the form exactly in figure 2. The cause of air cavities defect is almost the same as the cause of a needle defect. It is just that, the pattern and volume defect much larger. It often occurs when the permeability sand mold low and are able to flow water vapor / bubbles due to water with heat castings reaction. When the air bubbles stuck in the liquid metal castings, formed a broad shaped cavity. Once again, the pressure when making molds also influences defect air cavities establishment.

The calculation of the emergence of data defect mold fall out displayed in graphical form as in a figure 3 . The cause of a mold fall out one of them is the weakness of a bond between sand grains mold. The higher pressure of sand mold solidification will increasing the power of a

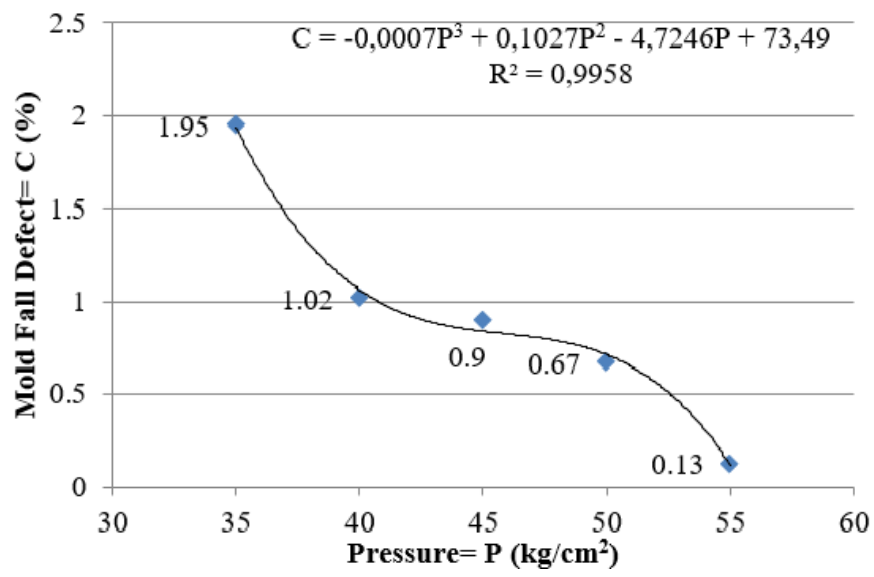

Figure 3. Variations pressure solidification of sand casting to mold fall defect

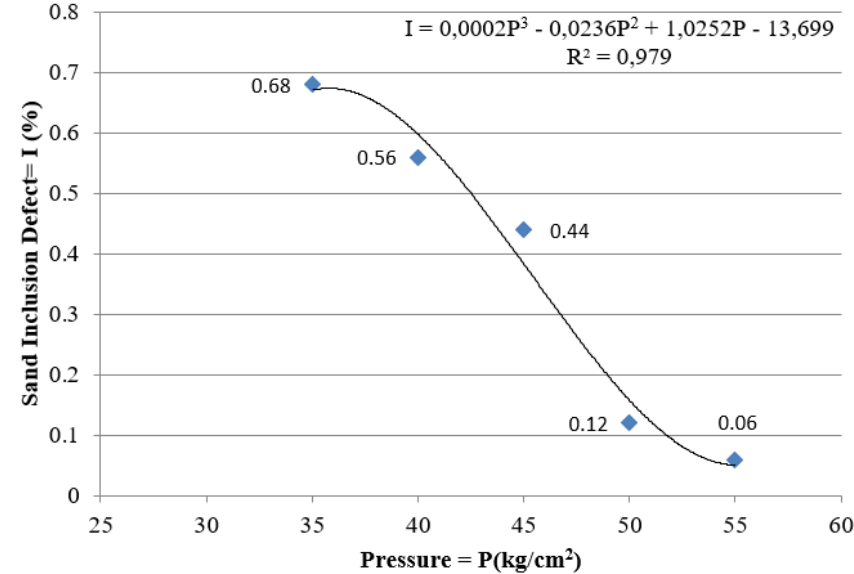

Figure 4. Variations pressure solidification of sand casting to sand inclusion defect

mold so the sand mold not easily fall out into the metal molten. Ammen [1], added one of the cause of this is the defect pressure the flow of metal that was so large can have just dropped a mold, this usually occurs when a bond between sand grains are too weak.

The calculation of the emergence data of sand inclusion defect displayed in graphical form as in a figure 4 The cause of the sand inclusion defect almost the same as the cause of a mold fall, that is because of the presence of sand grains into the Molten metal. The difference is, a mold fall caused the cavity in the surface and the sand will lost when the product was cleaned up, but the sand inclusion is fused with liquid metal. This Defect is very dangerous and affect the mechanical properties. To detect this defects in the castings can be used the X-Ray Radiography.

After finishing, castings are inspected for surface quality. Inspection can be performed manually by visual checking, manually by template comparison, or by an automated inspection station. Visual inspection is simple yet informative. A visual inspection would include significant

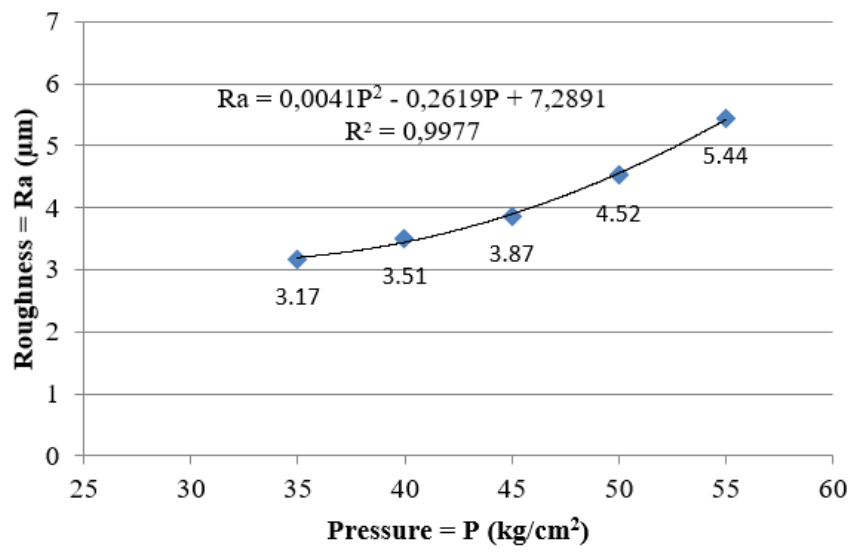

Figure 5. Relations variation pressure solidification of sand casting to the roughness 
dimensional measurements as well as general appearance. Surface discontinuities often indicate the presence of internal discontinuities [12]. Roughness test conducted in the three different spot for each specimens. The solidification of sand mold pressure variations influential as much as $99,77 \%$ on the perceived value of roughness of surface objects castings. Its influence in here is directly proportional, that is the great pressure then your valuation roughness ( term will also increase the greater the value it means the bristly ) objects. While the rest (0.23\%) influenced by other variables, such as: a measure of grain sand, the water level, as well as the shape of a channel in and exhaust ducts. The factor that influence the surface roughness is permeability. The higher the solidification of pressure will make the permeability decline and make the gases/ vapor will be stuck and influence the surface of a liquid metal. Gas can not get out and turned urged metal castings.

\subsection{Microstructure Formation}

The magnifications of microscopic examination of the casting is $500 \mathrm{X}$ using metalurgical microscope. The critical features found during visual examination should be studied at high magnification. It is most important that the features at the origin(s) be examined. The shape, size, and characteristics of the fine details should be studied and representative micrographs taken. Properties of a material depend on its microstructure, which is influenced by the processing and the type of manufacturing method, for example, casting, forging, and machining [4].

It is clear, therefore, that microstructure-based explanations are needed to account for the variation in wear rates with silicon content. Moreover, there is a need to account for the reduction in strength that occurs with increased silicon content [13] [14]. The complex effects of composition on wear behavior suggest that wear resistance depends on other material properties (for example, fracture toughness) [15]. After observation structure and compared with existing literature, identified several the building blocks from their each specimens. As for the result of the identification is presented in figure 6. The Figure also shows form of structure from the specimen, that can be used to predict the nature of fisis and mechanics. Heat consolidation (heat of fusion) and heat evaporation (heat of vaporization) the heat engine needed to withdraw or vaporize an ingredient have caused the changes atomic structure or molecules [16] on figures 6 . It appears that, the variation pressure compaction sand mold will affect structures of particles to reach the stage structure. This is because the quality of castings also had an influence on the cooling.

In figure 6 may be observed forms to the castings structure.The silicon be affected darker by influence etching [16]. The brightest a matrix aluminum pure that is soft. The white colored describing a perfect Al-Si also described a form of the point. Casting microstructure is determined by cooling rate, that is, how fast each part of the casting freezes. The cooling rate is roughly proportional to the ra-

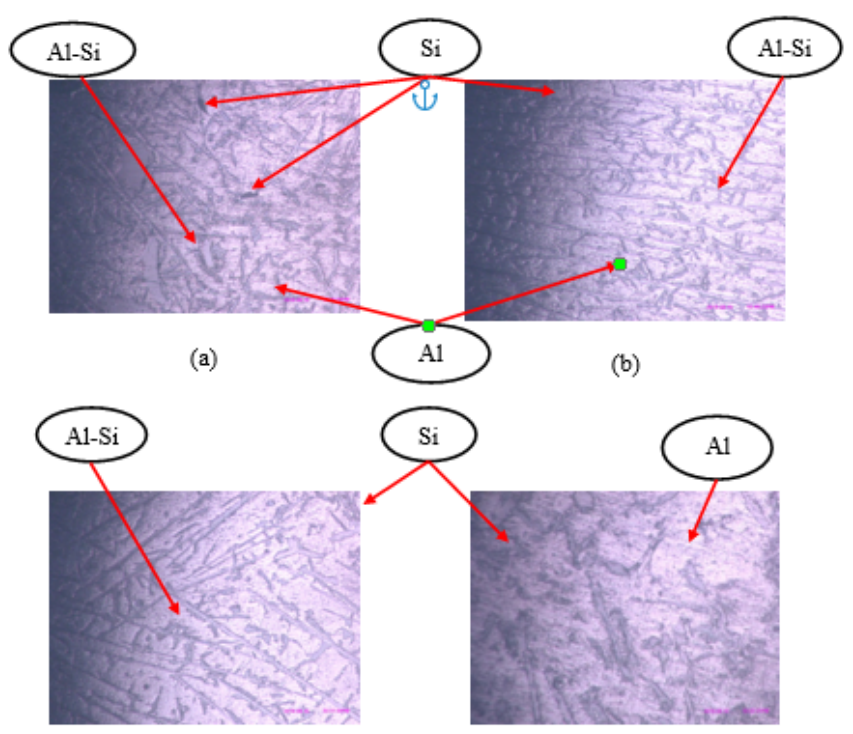

(c)

(d)

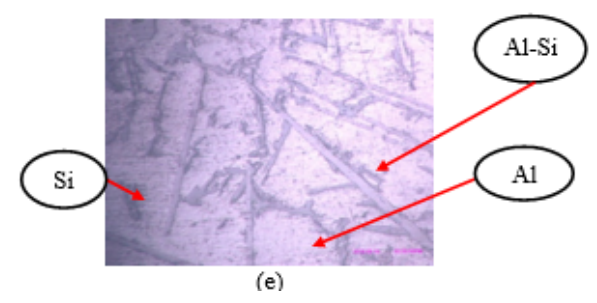

Figure 6. Micro photo pressure solidification sand mold sand casting (a) $35 \mathrm{~kg} / \mathrm{cm} 2$; (b) $40 \mathrm{~kg} / \mathrm{cm} 2$; (c) $45 \mathrm{~kg} / \mathrm{cm} 2$; (d) $50 \mathrm{~kg} / \mathrm{cm} 2$ (e) $55 \mathrm{~kg} / \mathrm{cm} 2$

tio of the square of the surface area of the casting to the square of its volume-a consequence of what metal casters know as Chvorinov's law. In other words, bulky castings freeze much slower than thin castings. For example, sphere of a given volume freezes more slowly than a thin plate of the same volume because the plate has much more surface area to transfer the same quantity of heat into the mold [9].

To variation pressure of $35 \mathrm{~kg} / \mathrm{cm}^{2}$ the grain structure is good and parallel, shaped similar as pearlite on carbon steel. Pearlite is a special blend consisting of two phase and formed when austenite with eutektoid composition transformed to ferrite and carbide [5]. The form of a structure in products castings with variations pressure 35 $\mathrm{kg} / \mathrm{cm}^{2}$ have the best hardness level. According to Vlack [16], at ordinary temperatures, the grains can hinder a shift. Hence, material with smooth grained more powerful than material rough grained.

At high temperatures, the grain can accommodate dislocation, so the situation is reversed, and it was creep. The higher pressure so a measure of grain is getting rough. So in variation $55 \mathrm{~kg} / \mathrm{cm}^{2}$, the form of structure is irregular, the grain is rudest. It usually been caused by coagulation of delays and affected by gases that stuck on the castings surface. There are many porosity / porous that can affect the level of castings violence. The pressure 
variation of mold solidfication can affect the solidfication rate (because permeability changing). As the solidification rate increases, the microstructure of the casting is refined. That is, the grains are smaller, and the spacing between the arms of the dendrites that make up grains is finer. Mechanical properties usually improve as the microstructure becomes finer. Because the properties depend on the microstructure, which depends on the solidification rate, which in turn depends on the processing variables used by the foundry and the casting design, designers have a major influence on the final properties of the casting [9].

\subsection{Mechanical Properties}

The mechanical test results, along with the microstructure, often confirm that the casting was properly heat treated. Mechanical testing should be done for most failure investigations, as knowing that the mechanical properties are acceptable is just as important as knowing that they are not [17]. The principal mechanism appears to be the influence of the hard silicon particles, which lead to higher overall levels of hardness. The fact that the hard silicon particles are surrounded by a softer and relatively tough matrix improves the overall toughness of the material and can contribute to wear resistance by favoring more plastic behavior.

For castings of some of the harder and stronger alloys, a hardness test is a good means of estimating the level of mechanical properties [12]. Hardness test done by the use of a micro vickers hardness tester with the force of $200 \mathrm{gf}$ and loading time 10 seconds. The diamond coneshaped Indentor out of the corner of face $136^{\circ}$, Hardness test performed on three points of the sampling method of who differ between each specimens. Hardness testing result shows in VHN (Vickers Hardness Number), that can be seen in figure 7. Explanation fuller about the degree of violence can be seen in the discussion micro structure, is the structure closely related to mechanical properties material.

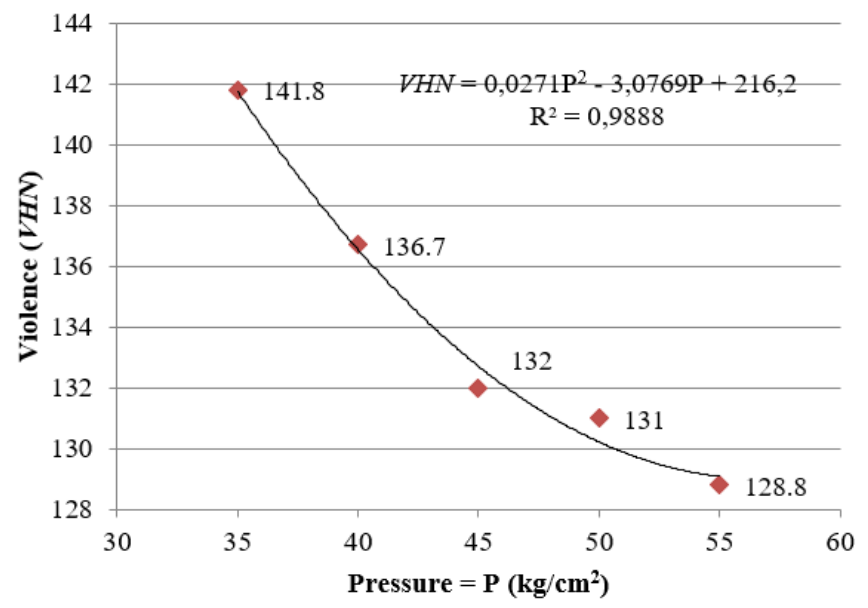

Figure 7. The solidification of sand mold relations pressure against violence

\section{Conclussions}

1. The solidification of pressure variations sand mold $45 \mathrm{~kg} / \mathrm{cm}^{2}$ produce castings products with the most optimal average in terms of the measurement of the defective;

2. The solidification of pressure variations sand mold $35 \mathrm{~kg} / \mathrm{cm}^{2}$ produce a smooth surface, and the higher pressure make surface castings becomes rougher;

3. The solidification of pressure variations sand mold $\mathrm{kg} / \mathrm{cm}^{2}$ produce micro structure with smooth grains and becomes rougher along with increasing pressure;

4. The solidification of pressure variations sand mold $\mathrm{kg} / \mathrm{cm}^{2}$ produce a hardest surface, the higher of the pressure variation it becoming violence number progressively lower.

\section{References}

[1] C. Ammen, The complete handbook of sand casting. Tab Books, 1979.

[2] D. S. M. Chen, XG and Gougeon., "A comparison of the quality of the outcome casting sand mold wet with a mixture of bentonite 3 grey," Journal of material science and engineering, pp. 174 - 184, 2009.

[3] M. Maleque, "The product quality analysis gokart rim of an alloy of aluminum castings," Journal of Mechanical engineering and sciences, vol. 10, pp. 175864, 2016.

[4] T. Surdia and k .Chijiwa, The technique of casting metals. Pradnya Paramita Jakarta, 2000.

[5] J. Lyle and D. Granger, Ullman's Encyclopedia of Industrial Chemistry, vol. 1A. VCH Publishers, 1985.

[6] E. Rooy, Aluminum and Aluminum Alloys Casting, vol. 15. Metals Handbook ASM International, 9 ed., 1988.

[7] T. Eyre, "Wear resistance of metals," in Treatise on Materials Science \& Technology, vol. 13, pp. 363-442, Elsevier, 1979.

[8] A. Kaye and A. Street, Die Casting Metallurgy. Butterworths Scientific, 1982.

[9] Casting Design and Processes. No. 9 - 36, ASM Handbook, 2009.

[10] P. Blau, Friction, Lubrication, and Wear Technology, vol. 18. ASM Handbook, 1992.

[11] M. N. Vijay SJ, "The influence of the water level sand mold on the quality of castings alloy of aluminium," Journal of material and design, vol. 31, pp. 3589-9, 2010. 
[12] Inspection of Castings Casting Design and Performance. No. 247-249, ASM Handbook, 2008.

[13] S. Das, S. Prasad, and T. Ramachandran, "Microstructure and wear of cast (al-si alloy)-graphite composites," Wear, vol. 133, no. 1, pp. 173-187, 1989.

[14] B. P. Bai, S. Biswas, and N. Kumtekar, "Scanning electron microscopy study of worn al-si alloy surfaces," Wear, vol. 87, no. 3, pp. 237-249, 1983.
[15] K.-H. Zum Gahr, Microstructure and wear of materials, vol. 10. Elsevier, 1987.

[16] L. H. V. Vlack, Elements Of Material Science And Engineering. Addison-Wesley, 5 ed., 1992.

[17] C. Brown, Casting Failure Analysis Techniques and Case Studies in Casting. ASM Handbook, 15 ed., 2008. 